\title{
Accidental ingestion and aspiration of foreign objects during dental practice
}

\author{
Dimitrios Dionysopoulos \\ Department of Operative Dentistry, School of Dentistry, Aristotle University of Thessaloniki, 54124 Thessaloniki, Greece.
}

Correspondence to: Dr. Dimitrios Dionysopoulos, Department of Operative Dentistry, School of Dentistry, Aristotle University of Thessaloniki, 54124 Thessaloniki, Greece. E-mail: ddiondent@gmail.com

How to cite this article: Dionysopoulos D. Accidental ingestion and aspiration of foreign objects during dental practice. Stomatological Dis Sci 2017; 1:87-9.

Article history: Received: 14 Sep $2016 \quad$ Accepted: 21 Sep $2016 \quad$ Published: 29 Sep 2017
from Aristotle University of Thessaloniki, Faculty of Dentistry with the degree of DDS, and he completed his Post-
graduate Program in Operative Dentistry. Later he received his PhD degree entitled "In vitro comparative study on
cariostatic effect of contemporary fluoride-releasing materials for conservative restorations" in Operative Dentistry
from Aristotle University of Thessaloniki. After that, he became a Research Associate and a clinical instructor at
the Department of Operative Dentistry of Aristotle University of Thessaloniki. He carried out a wide research and
has many publications in SCl covered local and international journals. He is an editorial member and reviewer in
various international journals and member of professional and scientific societies.

Accidental ingestion or inhalation of dental objects during daily clinical practice may cause various clinical complications such as damage to the digestive tract, abscess formation, peritonitis, septicemia, pneumonia, foreign-body granuloma, fistulas and duodenocolic fissures. ${ }^{[1]}$ The severity of the situation depends on the anatomical direction that the object followed and the anatomical location that may cause obstruction. Size, shape and sharpness of the objects determine the consequences which may be life-threatening. The risk of injury increases when the size of the swallowed object is more than $5 \mathrm{~cm}$ or has a pointed shape. ${ }^{[2]}$

In most of the cases, the foreign bodies pass through the gastrointestinal tract without difficulty, in $10-20 \%$ of the cases require non-surgical intervention, while $1 \%$ or less require surgical intervention to retrieve such foreign objects. ${ }^{[2]}$ In the literature there are many cases which have reported ingestion or aspiration of burs, endodontic posts, impression materials, temporary restorations, ${ }^{[3]}$ dental inlays or crowns, ${ }^{[4]}$ fixed ${ }^{[5]}$ or removable ${ }^{[6]}$ prosthetic restorations. It has also been reported that inter-occlusal devices used for the restoration of occlusion, ${ }^{[7]}$ air-water syringe tips, ${ }^{[8]}$ endodontic instruments including dental clamps, ${ }^{[9]}$ hand files or reamers, ${ }^{[10]}$ hypodermic needles, ${ }^{\left[{ }^{[11]}\right.}$ apex locator lip clips, ${ }^{[12]}$ orthodontic brackets and/appliances, ${ }^{[13]}$ and implant components ${ }^{[14]}$ have been aspirated.

Patients that have ingested dental objects during

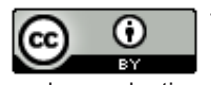
Lice This This is an open access article licensed under the terms of Creative Commons Attribution 4.0 International License (https://creativecommons.org/licenses/by/4.0/), which permits unrestricted use, distribution, and reproduction in any medium, as long as the original author is credited and the new creations are licensed under the identical terms.

For reprints contact: service@oaepublish.com

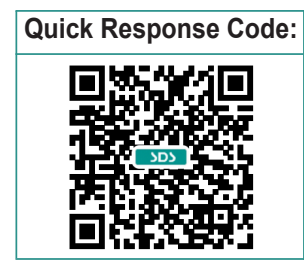


clinical practice experience considerable anxiety which usually makes the management of the situation difficult. When accidental ingestion of a foreign object occurs, the dental practitioner should immediately confirm that there are not any signs of obstruction to the throat such as dyspnea, choking, labored breathing or cyanosis. Subsequently, the dentist has to comfort the patient, explain the situation and refer the patient to the emergency room for radiographic examination to locate the exact position of the object. In some cases, a radiographic examination may not be enough to detect the exact location of the dental object. ${ }^{[15]}$ For this reason, more specific examinations may be needed such as fluoroscopy, which is an imaging technique that uses X-rays to obtain real-time moving images of the interior of an object. In the case of an object that is not radiopaque, diagnostic bronchoscopy or computed tomography for localization is indicated. ${ }^{[16]}$

Dentists have to be aware of patient-related factors which make the patient more prone to swallow foreign bodies, children, e.g. patients with an excessive gag reflex, small oral cavity, and short palate. Also patients with acroglossia, a thick neck, overweight patients, pregnant women, alcoholic patients or patients taking medication (especially those with psychiatric diseases. ${ }^{[13]}$ )

The prevention of such accidents is of great importance. The patients with the above characteristics should be informed and instructed to control the swallowing reflex if the object falls and then to turn the head to one side. Patients in whom the coordination of the deglutition and cough reflexes are affected, or the intra-abdominal pressure is increased should be treated in a more upright position. ${ }^{[3]}$

In endodontics, it is possible to minimize the risk of inhalation or ingestion of root canal instruments by using a rubber dam. The patient must be placed in an upright position to avoid swallowing of foreign objects and if possible to tether with a ligature any object which is prone for swallowing. ${ }^{[17]}$ Moreover, for radiographic examinations X-ray films or digital sensors should be tethered, or the use of the paralleling technique with a paralleling instrument may be more appropriate.

In most of the cases, the foreign objects pass through the gastrointestinal tract and are evacuated in two to five days without symptoms ${ }^{[18]}$ or may lodge in the duodenum or colon leading in some cases to severe pathological situations such as peritonitis. ${ }^{[19]}$ Consequently, it is necessary the patient be under medical surveillance until the evacuation of the object. In such cases, food with coarse fiber may be beneficial for pass through of foreign object.

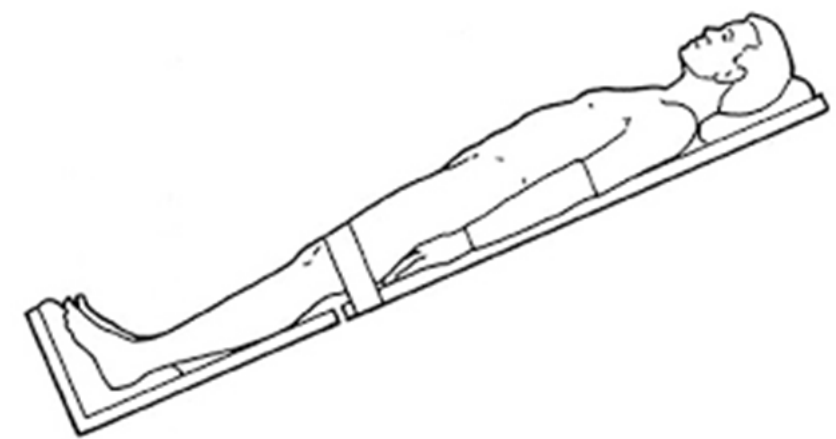

Figure 1: The reverse Trendelenburg position
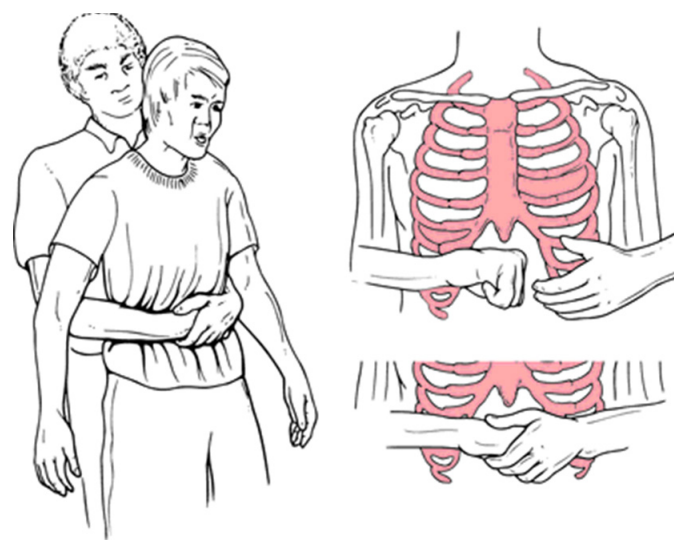

Figure 2: The Heimlich maneuver

Inhalation of a foreign object is a more serious condition than ingestion and dentist should be educated to manage it. Bronchoscopy has been demonstrated $99 \%$ effective on retrieve the aspirated dental objects. Nevertheless, the complication rate is between $2.4 \%$ and $5.0 \% .^{[20]}$ If a dentist realizes that a dental object dropped into the patient's oropharynx, she/he should place the patient in reverse Trendelenburg position (the upper part of the body is raised $20^{\circ}-30^{\circ}$ ) [Figure 1] and tell her/him to cough. If the object is not retrieved, the Heimlich maneuver should be followed [Figure 2], and if again there is no relief the patient should be transferred immediately to the nearest emergency room. ${ }^{[13]}$ If the patient is asymptomatic, he/ she should be reassured and informed calmly about the complication and the necessity of immediate medical examination. Frontal and lateral chest and abdominal radiographs should reveal whether the object has been ingested or inhaled. ${ }^{[3]}$

In conclusion, dentists have to be aware of precautions and educated for the management of an accidental swallowing or aspiration of foreign objects during clinical practice. More caution is necessary for patients that are prone to swallow foreign objects.

\section{Acknowledgments}

I would like to thank Dr. Jon Wagner for his contribution 


\section{in the language editing.}

\section{Financial support and sponsorship}

None.

\section{Conflicts of interest}

There are no conflicts of interest.

\section{Patient consent}

Not applicable.

\section{Ethics approval}

Not applicable.

\section{REFERENCES}

1. Hodges ED, Durham TM, Stanley RT. Management of aspiration and swallowing incidents: a review of the literature and report of case. ASDC J Dent Child 1992;59:413-9.

2. Webb WA. Management of foreign bodies of the upper gastrointestinal tract: update. Gastrointest Endosc 1995;41:39-51.

3. Zitzmann NU, Elsasser S, Fried R, Marinello CP. Foreign body ingestion and aspiration. Oral Surg Oral Med Oral Pathol Oral Radiol Endod 1999;88:657-60.

4. Tamura N, Nakajima T, Matsumoto S, Ohyama T, Ohashi Y. Foreign bodies of dental origin in the air and food passages. Int $J$ Oral Maxillofac Surg 1986;15:739-51.

5. Beaumont RH. Retrieval of a swallowed casting 6 weeks after ingestion. A case report. Oral Surg Oral Med Oral Pathol 1987;64:287-8.

6. Abusamaan M, Giannobile WV, Jhawar P, Gunaratnam NT. Swallowed and aspirated dental prostheses and instruments in clinical dental practice: a report of five cases and a proposed management algorithm. J Am Dent Assoc 2014;145:459-63.

7. Vasconcellos WA, Braga NM, Moretzsohn LD, Lanza MD, Lanza MD, Rocha WM. Accidental ingestion of an inter-occlusal device used for the restoration of occlusion: a case report. Oral Health Dent Manag 2014;13:854-6.

8. Tsitrou E, Germanidis G, Boutsiouki C, Koulaouzidou E, KoliniotouKoumpia E. Accidental ingestion of an air-water syringe tip during routine dental treatment: a case report. J Oral Sci 2014;56:235-8.

9. Mejia JL, Donado JE, Posada A. Accidental swallowing of a dental clamp. J Endod 1996;22:619-20.

10. Kuo SC, Chen YL. Accidental swallowing of an endodontic file. Int Endod J 2008;41:617-22.

11. Srivastava N, Pandit I, Nikhil V, Gugnani N. Accidental swallowing of a hypodermic needle. Int J Clin Pediatr Dent 2009;2:60-2.

12. Fishelberg G, Hook D. Patient safety during endodontic therapy using current technology: a case report. J Endod 2003;29:683-4.

13. Pingarrón Martín L, Morán Soto MJ, Sánchez Burgos R, Burgueño García M. Bronchial impaction of an implant screwdriver after accidental aspiration: report of a case and revision of the literature. Oral Maxillofac Surg 2010;14:43-7.

14. Pull Ter Gunne L, Wismeijer D. Accidental ingestion of an untethered instrument during implant surgery. Int J Prosthodont 2014;27:277-8

15. Frumkin K, Lanker M. Suspected esophageal coin - look again. Am J Emerg Med 2016;34:680.e3-4

16. Knowles JE. Inhalation of dental plates: a hazard of radiolucen materials. J Laryngol Otol 1991;105:681-2.

17. Tiwana KK, Morton T, Tiwana PS. Aspiration and ingestion in dental practice: a 10-year institutional review. $J$ Am Dent Assoc 2004;135:1287-91.

18. Christen AG. Accidental swallowing of an endodontic instrument. Oral Surg Oral Med Oral Pathol 1967;24:684-6.

19. Govila CP. Accidental swallowing of an endodontic instrument. A report of two cases. Oral Surg Oral Med Oral Pathol 1979;48:269-71.

20. Black RE, Johnson DG, Matlak ME. Bronchoscopic removal of aspirated foreign bodies in children. J Pediatr Surg 1994;29:682-4. 